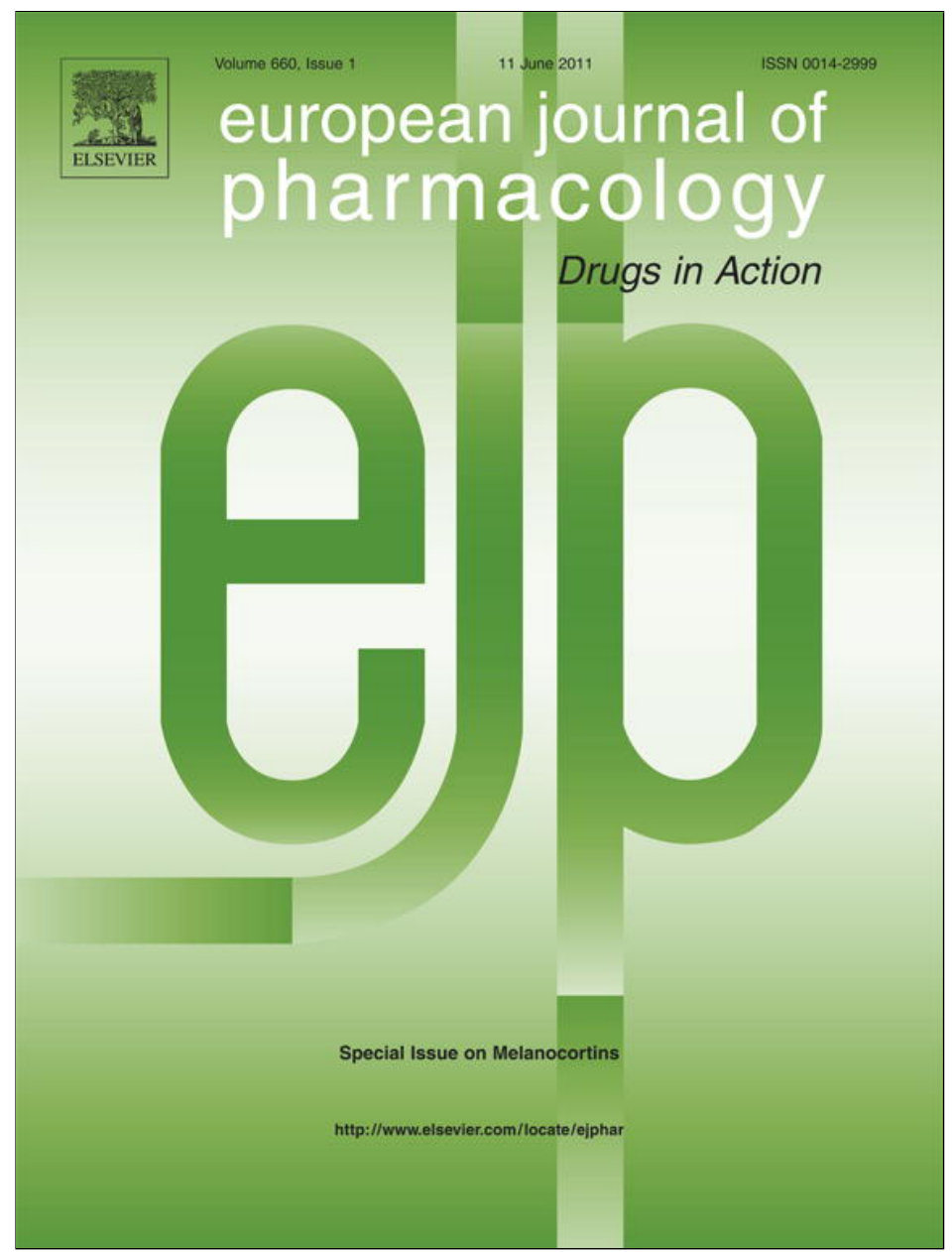

This article appeared in a journal published by Elsevier. The attached copy is furnished to the author for internal non-commercial research and education use, including for instruction at the authors institution and sharing with colleagues.

Other uses, including reproduction and distribution, or selling or licensing copies, or posting to personal, institutional or third party websites are prohibited.

In most cases authors are permitted to post their version of the article (e.g. in Word or Tex form) to their personal website or institutional repository. Authors requiring further information regarding Elsevier's archiving and manuscript policies are encouraged to visit:

http://www.elsevier.com/copyright 
Review

\title{
Association between melanism, physiology and behaviour: A role for the melanocortin system
}

\author{
Alexandre Roulin *, Anne-Lyse Ducrest \\ Department of Ecology and Evolution, University of Lausanne, Lausanne, Switzerland
}

\section{A R T I C L E I N F O}

\section{Article history:}

Received 25 August 2010

Received in revised form 22 December 2010

Accepted 13 January 2011

Available online 11 February 2011

\section{Keywords:}

Barn owl

Evolutionary biology

Glucocorticoid

Melanin-based coloration

Melanocortin system

\begin{abstract}
A B S T R A C T
The melanocortin system is implicated in the expression of many phenotypic traits. Activation of the melanocortin $\mathrm{MC}_{1}$ receptor by melanocortin hormones induces the production of brown/black eumelanic pigments, while activation of the four other melanocortin receptors affects other physiological and behavioural functions including stress response, energy homeostasis, anti-inflammatory and sexual activity, aggressiveness and resistance to oxidative stress. We recently proposed the hypothesis that some melanocortin-physiological and -behavioural traits are correlated within individuals. This hypothesis predicts that the degree of eumelanin production may, in some cases, be associated with the regulation of glucocorticoids, immunity, resistance to oxidative stress, energy homeostasis, sexual activity, and aggressiveness. A review of the zoological literature and detailed experimental studies in a free-living population of barn owls (Tyto alba) showed that indeed melanic coloration is often correlated with the predicted physiological and behavioural traits. Support for predictions of the hypothesis that covariations between coloration and other phenotypic traits stem from pleiotropic effects of the melanocortin system raises a number of theoretical and empirical issues from evolutionary and pharmacological point of views.
\end{abstract}

(c) 2011 Elsevier B.V. All rights reserved.

\section{Contents}

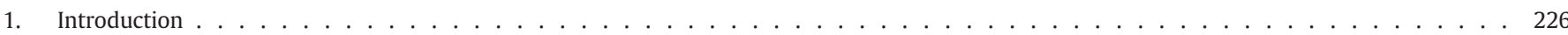

2. Pleiotropy in the melanocortin system. . . . . . . . . . . . . . . . . . . . . . . . . . . . . . . . . . . . . . 227

3. Covariation between melanin-based coloration and other phenotypic attributes in the barn owl. . . . . . . . . . . . . . . . . . . 228

3.1. Prediction 1: compared to pale individuals, darker eumelanic conspecifics are more resistant to stressful factors that induce a glucocorticoid response . . . . . . . . . . . . . . . . . . . . . . . . . . . . . . . . . . . . . . . . 228

3.2. Prediction 2: compared to pale individuals, darker eumelanic conspecifics have reduced inflammatory responses and higher proliferation of B cells and regulatory T cells . . . . . . . . . . . . . . . . . . . . . . . . . . . . . . . . 228

3.3. Prediction 3: compared to pale individuals, darker eumelanic conspecifics better regulate the balance between food intake and energy expenditure . . . . . . . . . . . . . . . . . . . . . . . . . . . . . . . . . . . . 228

3.4. Prediction 4: compared to pale individuals, darker eumelanic conspecifics are more resistant to oxidative stress . . . . . . . . . 230

3.5. Prediction 5: compared to pale individuals, darker eumelanic conspecifics are sexually more active. . . . . . . . . . . . . . . 230

4. Implications . . . . . . . . . . . . . . . . . . . . . . . . . . . . . . . . . . . 230

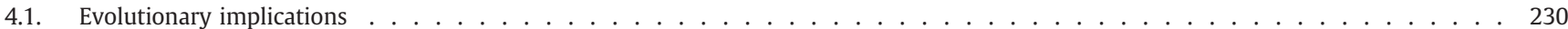

4.2. Pharmacological implications . . . . . . . . . . . . . . . . . . . . . . . . . . . . . . . . . . . . 232

Acknowledgements . . . . . . . . . . . . . . . . . . . . . . . . . . . . . . . . . . . . . . . . . . . . . 232

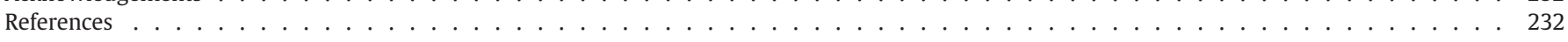

\section{Introduction}

Anyone who opens a book about animal identification will be fascinated by the extreme diversity of shapes, forms and coloration. A

\footnotetext{
* Corresponding author. Tel.: +41 7968608 64; fax: +41 216924165 . E-mail address: Alexandre.Roulin@unil.ch (A. Roulin).
}

striking fact is that a large number of yellow, reddish, black, blue and grey traits that vary between and within species are due to differential deposition of melanin pigments. Studying melanogenesis is useful to understand the evolution, maintenance and adaptive function of melanin-based colour traits. For instance, mutations at a single gene can account for geographic variation in coat colour in mice (Mullen and Hoekstra, 2008) and humans (Valverde et al., 1995; Rees, 2003). 
Furthermore, in many vertebrates dark and pale conspecifics differ in physiology and behaviour, an observation that led evolutionary biologists to dive in the vast pharmacological, genetic and medical literature to understand the causes and consequences of the link between coloration and other phenotypic attributes (Ducrest et al., 2008; Galvan and Alonso-Alvarez, 2008; Jablonski and Chaplin, 2010). Knowledge of the pleiotropic effects of the melanocortin system appears useful to propose predictions about how melanin-based coloration may covary with physiological and behavioural traits. This is a key aspect for understanding the role played by coloration in social interactions. For example, if dark melanic coloration is associated with resistance to pathogens, dark coloration may be favoured evolutionarily over paler conspecifics under both natural and sexual selection.

Recently, we proposed that the melanocortin system could explain why within populations of wild vertebrates melanin-based coloration is often associated with variation in physiology and behaviour (Ducrest et al., 2008). Melanogenesis is controlled by the melanocortin system that consists of the melanocortin $\mathrm{MC}_{1}$ receptor and its ligands: the melanocortins (i.e., melanin stimulating hormones $\alpha-, \beta$, $\gamma$-MSHs and the adrenocorticotropin hormone ACTH) and the inverse agonist/antagonist, the agouti signalling protein (ASIP). This proposition can apply only to species for which inter-individual variation in melanin-based coloration is due to the melanocortin system. Our hypothesis may thus not apply to human because there are many mutations in different genes, but not in the POMC and ASIP genes, implicated in the control of human skin, hair and eye coloration (Sturm, 2006).

Here, we review the pleiotropic effects of the melanocortin system, and then dwell into the empirical evidences about whether the covariance between melanic coloration and other phenotypic traits are compatible with the pleiotropic effects of the melanocortin system. Finally, we discuss some theoretical and empirical consequences of pleiotropic effects of the melanocortin system from an evolutionary and pharmacological perspective.

\section{Pleiotropy in the melanocortin system}

Melanocortins are posttranslational bioactive peptides encoded by the proopiomelanocortin $(P O M C)$ gene. They have neuroendocrine and paracrine functions through binding to five tissue-specific melanocortin receptors $\mathrm{MC}_{1-5}$, which are well conserved among vertebrates (Schioth et al., 2005). The various melanocortins have different affinities for the five receptors with the exception of $\mathrm{MC}_{2}$ receptor for which $\mathrm{ACTH}$ is the only ligand. Through binding to the five receptors melanocortins regulate physiological functions including melanogenesis, stress response, energy homeostasis, anti-inflammatory response, sexual activity, resistance to oxidative stress and aggressiveness. In a recent paper (Ducrest et al., 2008), we reviewed 270 papers reporting the phenotypes displayed by full and conditional knockout mice of POMC, Mc1-5r and AGRP genes (in total these studies examined 99 potential physiological effects), by transgenic mice over-expressing POMC, ASIP, $A G R P$ genes and by dominant mutant agouti mice ( 41 effects) and by animals injected with melanocortins and their analogues (389 effects) or with antagonists of melanocortins and their analogues (89 effects). The full list of the considered studies can be found in the supplementary Table S1 of the journal Trends in Ecology and Evolution (doi:10.1016/j. tree.2008.06.001).

This review of the pharmacological and genetic literature showed that manipulation of the genes of the melanocortin system or of their products recurrently affects a suite of phenotypic traits. Table 1 indicates whether a given phenotype will be more $(+)$ or less $(-)$ expressed if the activity of melanocortin receptors is higher. For example, higher activity of $\mathrm{MC}_{1}$ receptor triggers the synthesis of eumelanogenesis and reduces pheomelanogenesis, while higher activity of $\mathrm{MC}_{2}$ receptor stimulates the synthesis of glucocorticoids. We

\section{Table 1}

Summary of the positive and negative pleiotropic effects obtained by manipulation of key components of the melanocortin system. The symbols + and - indicates that when the activity of melanocortin receptors is enhanced, a given phenotype is expressed to a higher and lower level, respectively. For instance, higher activity of $\mathrm{MC}_{1}$ receptor due to $\alpha$-MSH leads to a shift in melanogenesis to higher production of eumelanin pigments (indicated by + ) at the expanse of pheomelanin pigments (indicated by - ).

\begin{tabular}{ll}
\hline Phenotypes & Effect \\
\hline Melanogenesis & + \\
$\quad$ Eumelanogenesis & - \\
$\quad$ Pheomelanogenesis & + \\
Sexual behaviour & + \\
Aggressiveness & + \\
Exocrine gland activity & \\
HPA stress response: & + \\
Basal activity (ACTH) & + \\
Resistance to a stressor (MSH) & \\
Immune function & + \\
$\quad$ Anti-inflammatory activity: reduction of acute, allergic & \\
$\quad$ and systemic inflammation and septic shock, increase & + \\
in proliferation of B and regulatory T cells & + \\
Antipyretic activity & \\
Resistance to oxidative stress & \\
Energy homeostasis and cardiovascular tone & - \\
$\quad$ Appetite & + \\
Thyroid hormone activity & + \\
Metabolic rate, blood pressure, heart rate and physical activity & - \\
Adult adipose tissue and body weight & - \\
Glycemia, insulinemia and leptinemia & + \\
Insulin sensitivity & + \\
Diet-induced thermogenesis & + \\
Grooming, stretching and yawning behaviour & + \\
\hline & + \\
\hline
\end{tabular}

speculate that under some circumstances these different functions may be correlated among each other, e.g. dark and pale melanic individuals may differentially regulate glucocorticoid plasma levels as shown in the barn owl (Tyto alba) (Almasi et al., 2010). Melanocortinbased covariation between melanin coloration and other phenotypic traits relies on three assumptions: (1) colour variation is not due to mutations at the $\mathrm{MC}_{1}$ receptor or downstream effectors, which have few pleiotropic effects, (2) but to differential activity of the POMC derived peptides or their antagonist ASIP, and (3) that the level of activity of the different melanocortins are correlated across tissues. Unfortunately, there is little information on such correlations because melanocortins act at specific time windows (Slominski et al., 2000), are rapidly degraded in the blood and poorly cross the blood-brain barrier (Eberle, 1988). However, recent studies indicated that the activity of the melanocortin system can be locally regulated and coordinated across organs by neuroendocrine communication (Slominski and Wortsman, 2000; Slominski, 2005; Zbytek et al., 2006). For instance, in the artic charr (Salvenus alpinus) stress due to social subordination results in increased in plasma concentration of $\alpha$-MSH and ACTH concentration and in skin darkening (Hoglund et al., 2000).

Based on the observation that melanocortin hormones and their antagonists not only regulate the activity of $\mathrm{MC}_{1}$ receptor but also of the other melanocortin receptors which induce a number of phenotypic effects (Table 1), we propose the following seven predictions regarding how the degree of eumelanic coloration may covary with other phenotypic traits in vertebrates. Compared to pale individuals, darker eumelanic conspecifics may be predicted (1) to be more resistant to stressful factors that induce a glucocorticoid response, (2) to reduce inflammatory responses and increase B and regulatory $\mathrm{T}$ cells proliferation, (3) to better regulate the energy balance between food intake and energy expenditure, (4) to be more resistant to oxidative stress, (5) to be sexually more active, (6) to be more aggressive, and (7) to have higher exocrine gland function for instance to spread lipids on the fur (Ducrest et al., 2008). These predictions may result from colour-related differential expression of the POMC gene or processing of the POMC prohormone, or from polymorphism in the POMC sequence (in the barn owl this gene is 
polymorphic with 10 to 24 serine repeats located in the $\gamma$-3-MSH, unpubl. data).

\section{Covariation between melanin-based coloration and other phenotypic attributes in the barn owl}

The above predictions about associations between melanin-based coloration and other phenotypic attributes are derived mostly from studies on laboratory animals. Given that the melanocortin system is highly conserved in vertebrates, conclusions derived from these studies may be applicable to wild organisms. As evolutionary biologists, we are interested in examining these predictions in wild animals to determine whether the melanocortin system may be implicated in the evolution and maintenance of the diversity in phenotypes observed in nature. In order to assess the relevance of our predictions, we reviewed empirical studies in wild animals ( 3 mammals, 36 birds, 4 fish, 4 reptiles and one amphibian). Accordingly, we found consistent association in the sign of covariation between melanic coloration and 5 physiological traits (sexual activity, aggressiveness, resistance to stressors, metabolic rate and body mass, and immune response against non-pathogenic antigen) in 43 out of 53 studies (Ducrest et al., 2008).

To further appraise the potential role of the melanocortin system in generating covariations between melanin-based coloration and other phenotypic attributes, we studied a free-living population of barn owls in Switzerland during more than 15 years. This bird is particularly interesting because its body underside varies from immaculate to marked with black eumelanic spots of varying size. Inter-individual variation in plumage traits is genetically determined, i.e. individuals display large black spots because they possess the necessary genes to produce eumelanic pigments and not because they eat particular food or have experienced specific environmental conditions (Roulin and Dijsktra, 2003; Roulin et al., 2010). Owls are nocturnal and hide during daylight hours, and hence the function of melanic pigments is not to protect the body against UV light as in humans (Jablonski and Chaplin, 2010). Finally, the degree of melaninbased coloration plays a role in mate choice and investment in reproduction, and adjustment of offspring sex ratio (Roulin, 1999; Roulin and Altwegg, 2007; Roulin et al., 2010).

Investigating the role of the melanocortin system in generating covariation between melanin-based coloration, physiological attributes and behaviour requires a number of studies. The first step is to investigate whether differently coloured individuals differ in phenotypic traits as predicted by the hypothesis based on the pleiotropic effects of the melanocortin system (Table 1). We thus measured physiological and behavioural traits in relation to the size of black eumelanic spots in free-living barn owls. To distinguish genetically from environmentally mediated covariation between coloration and other phenotypic attributes, we randomly allocated genotypes among the full range of habitats that are exploited by the considered species. To this end, we swapped barn owl eggs or hatchlings between randomly chosen pairs of nests. If plumage traits of foster and biological parents are not correlated, the potential correlation between rearing conditions and genetically-inherited plumage traits expressed by the nestlings is broken down. These so-called crossfostering experiments were performed from 1996 to 2007 using 332 broods.

\subsection{Prediction 1: compared to pale individuals, darker eumelanic conspecifics are more resistant to stressful factors that induce a glucocorticoid response}

After a standardized stressful event induced by handling nestlings during $26 \mathrm{~min}$, they released less corticosterone when their biological mother displayed large than small black spots (Fig. 1A). Additionally, two days after having experimentally administrated corticosterone by implanting a corticosterone-releasing pellet (Müller et al., 2009), the baseline level was lower in nestlings born from large- than small-spotted mothers (Fig. 1B) (Almasi et al., 2010). This suggests that barn owls displaying larger black spots return quicker to baseline corticosterone level after a stress-induced rise in the level of this hormone. Therefore, larger-spotted individuals may better cope with the negative impact of stressinduced rise in corticosterone level. To test this hypothesis we performed two experimental studies. First, we measured growth rate in body mass and wing length in nestling barn owls subcutaneously implanted with a pellet that released corticosterone within the natural physiological range during two days (Müller et al., 2009). As expected, growth rate in body mass and wing length was faster in large- than small-spotted nestlings (Fig. 1C) (Almasi et al., in prep.). Second, we administrated corticosterone in breeding males and measured the rate of provisioning food to their brood during the next four nights. Corticosterone-implanted males fed on average $68 \mathrm{~g}$ of prey mass per night less than placebo-males (mean prey mass per night is $281 \mathrm{~g}$ versus $349 \mathrm{~g}$ ). Interestingly, males displaying small black spots suffered a greater corticosteroneinduced reduction in provisioning rate than males with larger spots (Fig. 1D) (Almasi et al., 2008). Higher resistance to stress by darker eumelanic individuals may explain why darker owls develop a more symmetric phenotype, i.e. the length of the feathers of the left wing more closely matched the length of the feathers of the right wing in individuals born from large- than small-spotted mothers (Fig. 1E) (Roulin et al., 2003). From these studies, we conclude that darker eumelanic barn owls better regulate glucocorticoidmediated stress response and more generally better cope with a rise in corticosterone.

\subsection{Prediction 2: compared to pale individuals, darker eumelanic conspecifics have reduced inflammatory responses and higher proliferation of $B$ cells and regulatory $T$ cells}

We investigated humoral immunity by vaccinating barn owl nestlings with non-pathogenic and non-replicating antigen (sheep red blood cells). We collected a blood sample a couple of days later to quantify the antibodies specifically directed towards this vaccine. Nestlings born from mothers displaying larger eumelanic spots mounted a stronger antibody response (Fig. 2A) (Roulin et al., 2000). To examine whether the size of black spots also predicts resistance to blood-sucking ectoparasites, we measured the fecundity of ectoparasitic flies, Carnus hemapterus, collected on crossfostered nestlings (complete clutches were cross-fostered between nests so that flies were in contact with nestlings of one origin only). Flies are found in $97 \%$ of the nests with a mean number of 39 flies per nestling (range is 0 and 208), and each individual parasite lays up to 109 eggs (Roulin et al., 2007). As expected, flies were less fecund when collected on nestlings born from mothers displaying large than small black spots (Fig. 2B) (Roulin et al., 2001; Roulin, 2004).

3.3. Prediction 3: compared to pale individuals, darker eumelanic conspecifics better regulate the balance between food intake and energy expenditure

To test a potential association between coloration and the ability to withstand food depletion, we brought nestling barn owls to the laboratory to measure appetite and resistance to food depletion. In line with this hypothesis, nestlings fed ad libitum over a period of $24 \mathrm{~h}$ consumed fewer mice when displaying large than smaller black spots (Fig. 3A), and when food-deprived during $24 \mathrm{~h}$ they lost less weight (Fig. 3B) (Dreiss et al., 2010). Thus, darker eumelanic individuals may better regulate the balance between food intake and energy expenditure, and hence be better 
A

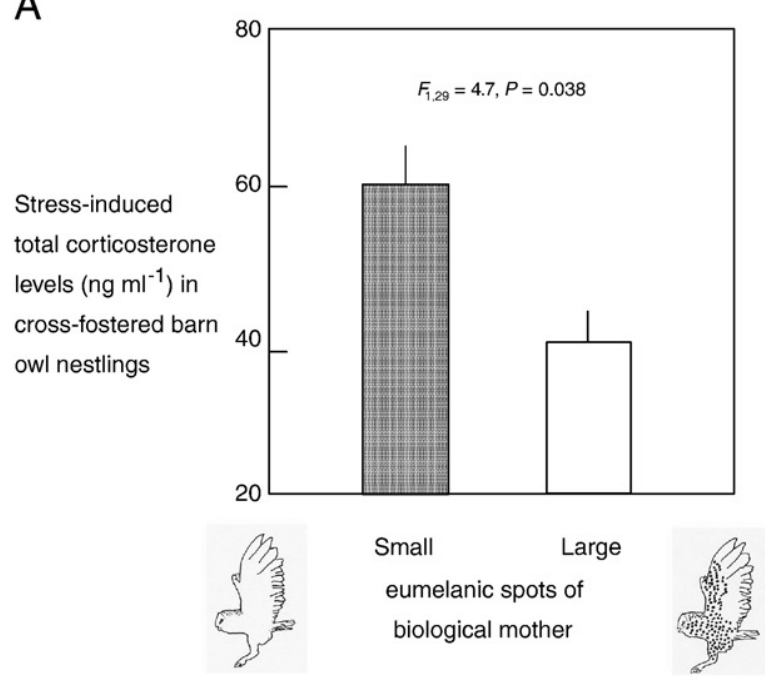

C

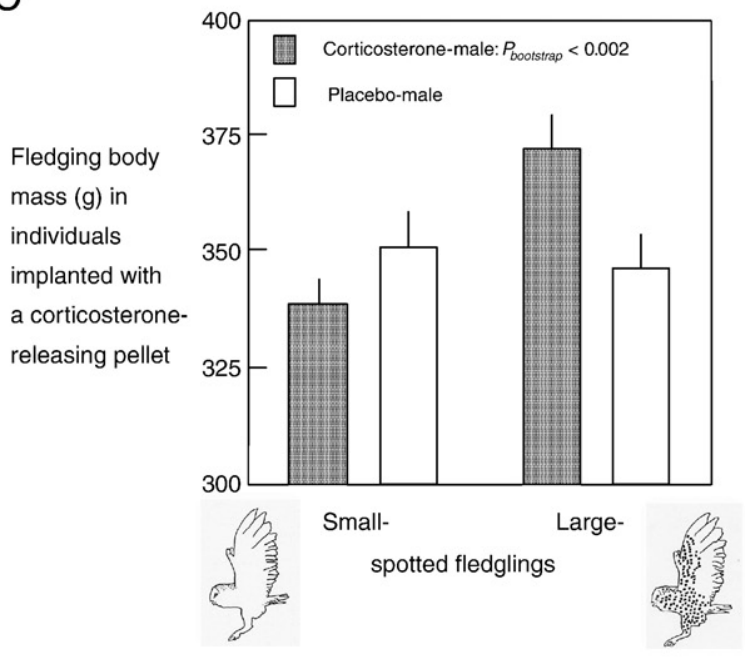

E

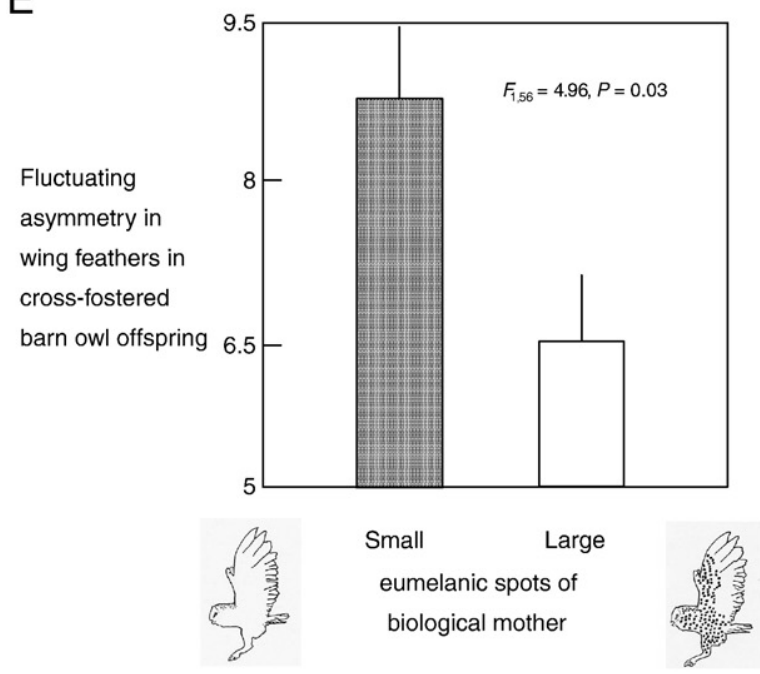

B

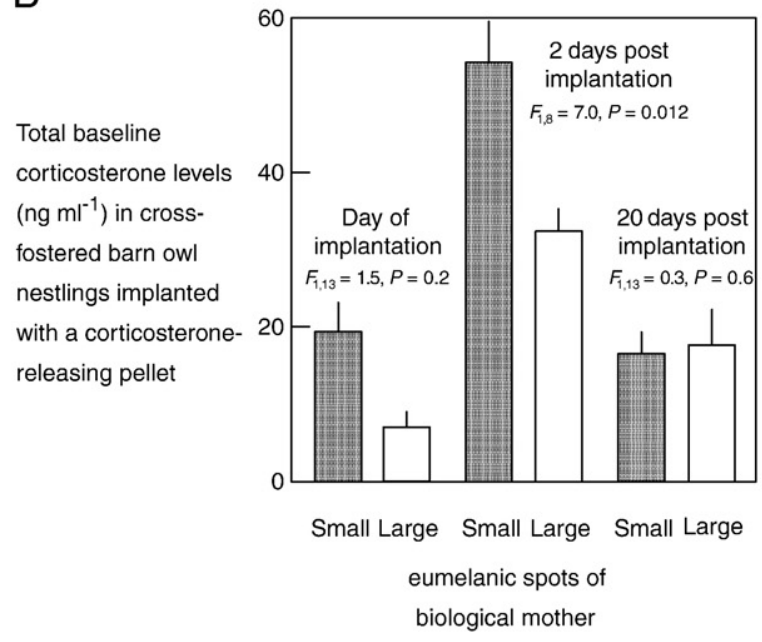

D

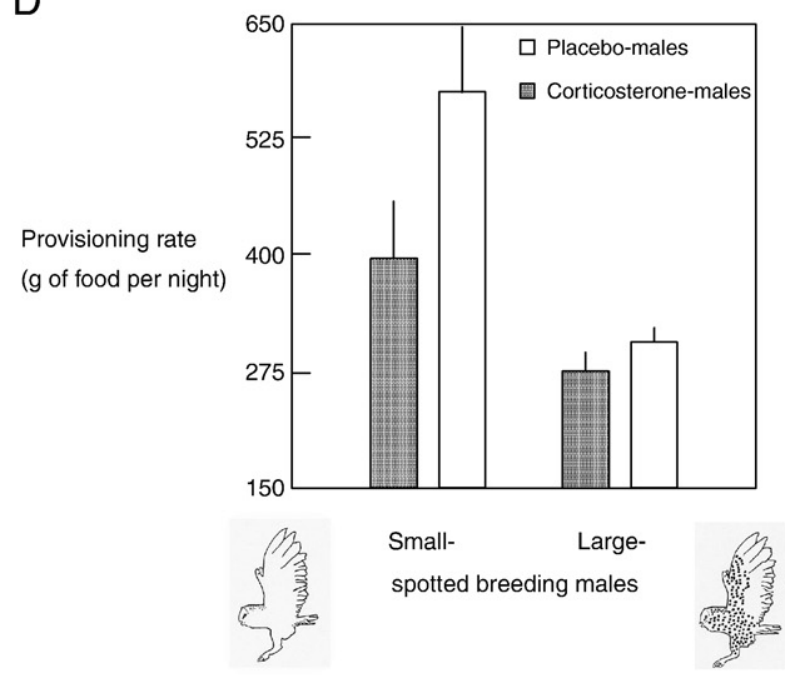

Fig. 1. Experimental tests of the prediction that dark eumelanic barn owls are more resistant to stressful factors that induce a glucocorticoid response than paler conspecifics. (A) Offspring raised by foster parents produce less corticosterone after a standardized stressful event when their biological mother displays small than large black spots (adapted from Almasi et al., 2010). (B) Baseline-total corticosterone levels in offspring raised by foster parents and implanted with a corticosterone-releasing pellet is lower when their biological mother displays large than small black spots (adapted from Almasi et al., 2010). (C) Among nestlings for which a corticosterone-releasing pellet was implanted subcutaneously at 29 days of age, those that displayed large black spots were heavier 20 days later than individuals showing small black spots (adapted from Almasi et al., in prep.).

(D) Compared to males implanted with a placebo-pellet, males implanted with a corticosterone-releasing pellet reduced the amount of food brought per night to their brood to a larger extent when small- than large-spotted (adapted from Almasi et al., 2008). (E) Offspring raised by foster parents develop a more symmetric phenotype (so-called fluctuating asymmetry) when their biological mother displays large than small black eumelanic spots (adapted from Roulin et al., 2003). 
A

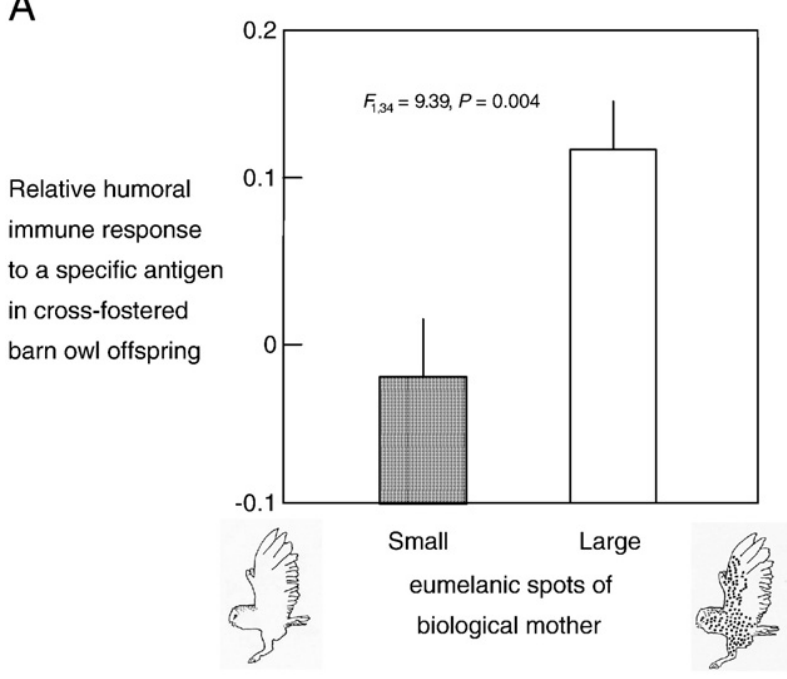

B

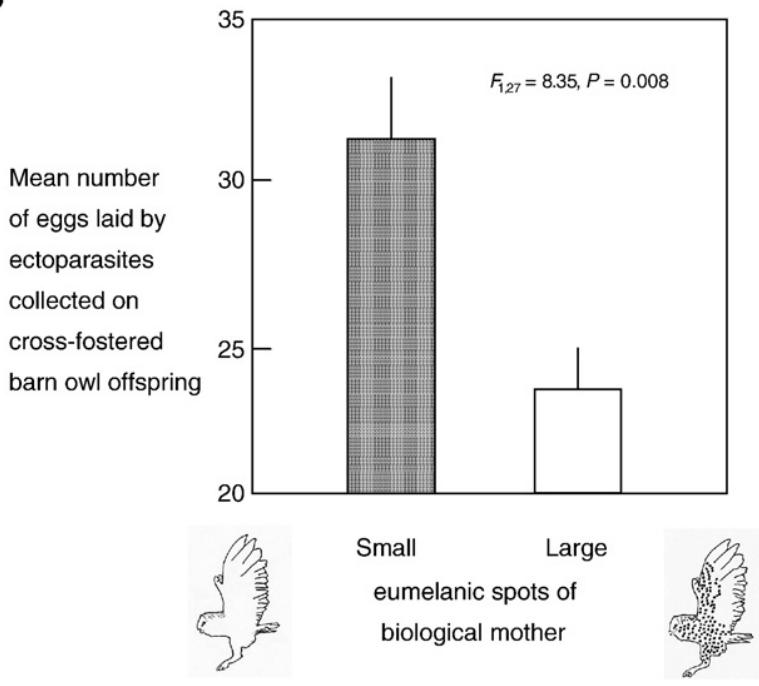

Fig. 2. Experimental test of the prediction that compared to pale individuals, darker eumelanic barn owls have reduced inflammatory responses and higher proliferation of B cells and regulatory $\mathrm{T}$ cells. (A) Offspring raised by foster parents produced more antibodies specifically directed against a vaccination (sheep red blood cells) when their biological mother displays large than small black eumelanic spots (adapted from Roulin et al., 2000). (B) Ectoparasitic flies (Carnus hemapterus) collected on offspring raised by foster parents lay fewer eggs when the biological barn owl mother displays large than small black eumelanic spots (adapted from Roulin et al., 2001 and Roulin, 2004).

able to withstand periods of food depletion. This conclusion is consistent with the finding that females displaying large black spots were heavier than conspecifics with smaller spots in the afternoon (i.e. a long time after the last feeding) but not in the morning (i.e. a short time after the last feeding) (Fig. 3C) (Roulin, 2009).

3.4. Prediction 4: compared to pale individuals, darker eumelanic conspecifics are more resistant to oxidative stress

Resistance to oxidative stress was measured as the time needed to hemolyze $50 \%$ of the red blood cells exposed to a controlled attack by reactive oxygen species using the KRL bioassay. A rapid lyse of red blood cells indicates low resistance of the red cell membrane to a thermo-controlled oxidative attack. We thus collected blood samples in individuals raised by foster parents and found, as predicted, that resistance of nestling red blood cells to oxidative stress was higher in families where nestlings harboured larger eumelanic spots (Fig. 4) (unpubl. data).

\subsection{Prediction 5: compared to pale individuals, darker eumelanic conspecifics are sexually more active}

Females displaying larger black spots started to breed for the first time at a younger age than individuals with smaller spots, a finding that was not significant in males (Fig. 5). This suggests that sexual maturity is reached earlier in darker eumelanic females (Roulin and Altwegg, 2007).

\section{Implications}

The hypothesis that the melanocortin system generates covariations between melanin-based coloration, physiological and behavioural traits have several implications from evolutionary and pharmacological perspectives.

\subsection{Evolutionary implications}

The melanocortin system regulates many physiological functions including coloration, sexual behaviour, aggressiveness, exocrine gland activity, HPA stress response, immunity, energy homeostasis and resistance to oxidative stress (Table 1 ). As a consequence of the coregulation of these traits by the same set of hormones and their antagonists, the activity of these functions is predicted to covary. Thus, under certain environmental conditions investment in these diverse functions may be energetically costly which could favour reduced expression of the POMC gene. Accordingly, animals adjust melanocortin levels in relation to environmental or social factors and to life stages (Ellis et al., 2008; Palermo et al., 2008). For instance, when exposed to food deprivation laboratory animals usually decrease the expression of the POMC gene (Myers et al., 2005; Dallman et al., 1999; Bertile et al., 2003; Schwartz and Porte, 2005; but see Kappeler et al., 2004). We carried out a study to investigate whether environmentally-induced variation in POMC gene expression differs between individuals displaying different degrees of melaninbased coloration (Gasparini et al., 2009). We considered the tawny owl (Strix aluco) because conspecifics vary in the degree of pheomelanin-based coloration, some individuals displaying a dark reddish plumage and others a non-reddish coloration. To test whether regulation of the POMC prohormone is colour-specific, we measured it (Rousseau et al., 2007) in breeding tawny owl females involved in a brood size manipulation experiment, i.e. females raised a brood for which we either added or removed one hatchling out of two to five hatchlings. Brood size manipulation is an appropriate way to induce changes in the level of parental workload and thus modify the level of stress experienced by parents. When brood size was experimentally reduced the POMC prohormone was circulating at a higher level in the blood of pale than dark reddish females, while when brood size was enlarged there was no significant relationship between the POMC prohormone and coloration (Roulin et al., in press). Our observation suggests that dark reddish individuals invest resources in phenotypes regulated by melanocortins relatively independently of changes in the environment, while pale conspecifics regulate these traits more finely in relation to variation in environmental factors. This calls for integrative studies where the level of melanocortins is measured in relation to melanin-based coloration and environmental or social factors, but also the phenotypic traits regulated by melanocortins. The final stage will be to manipulate melanocortin levels to examine the fitness consequences of up-regulating melanocortin-dependent phenotypic traits in differently coloured individuals. These studies will help understand the adaptive function of variation in pheomelanin-based coloration but also variation in the expression of the POMC gene. 
A

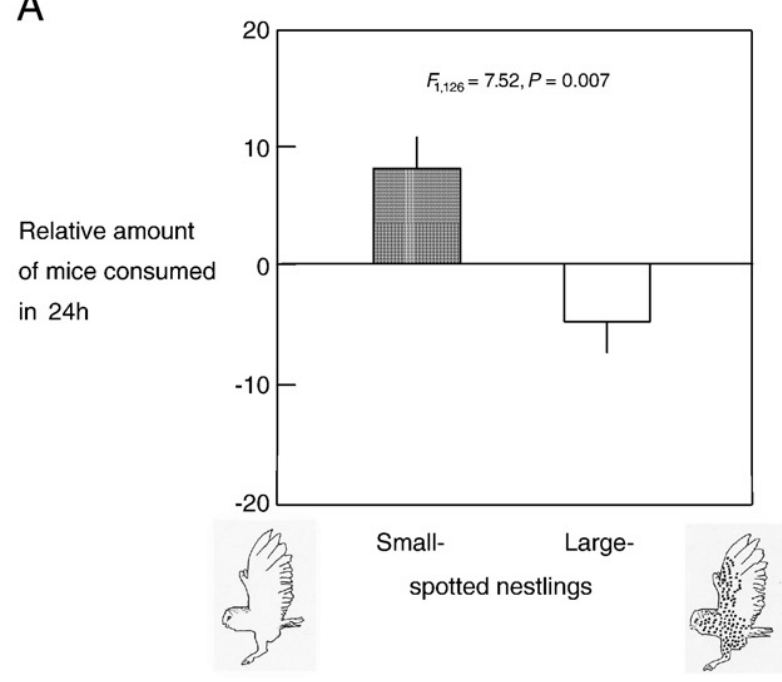

B

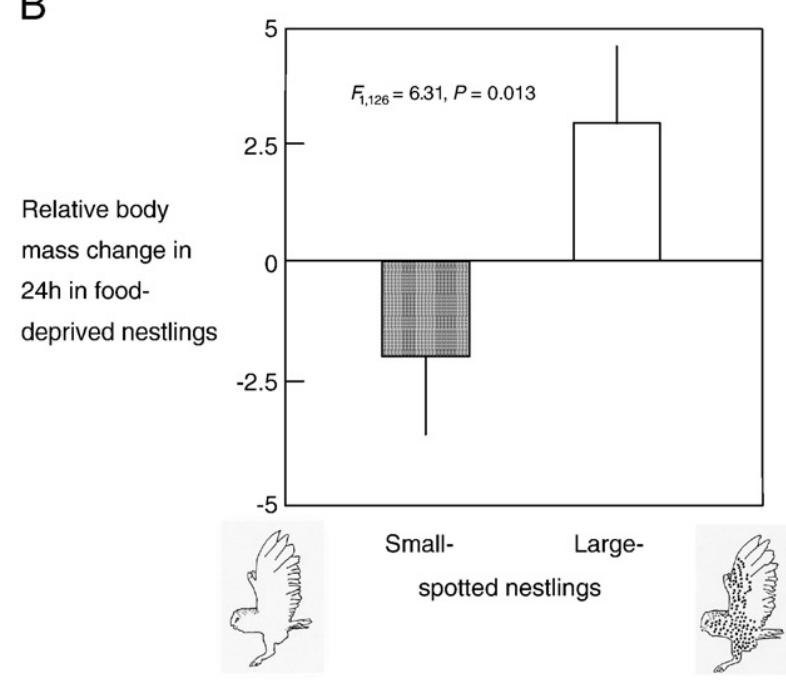

C

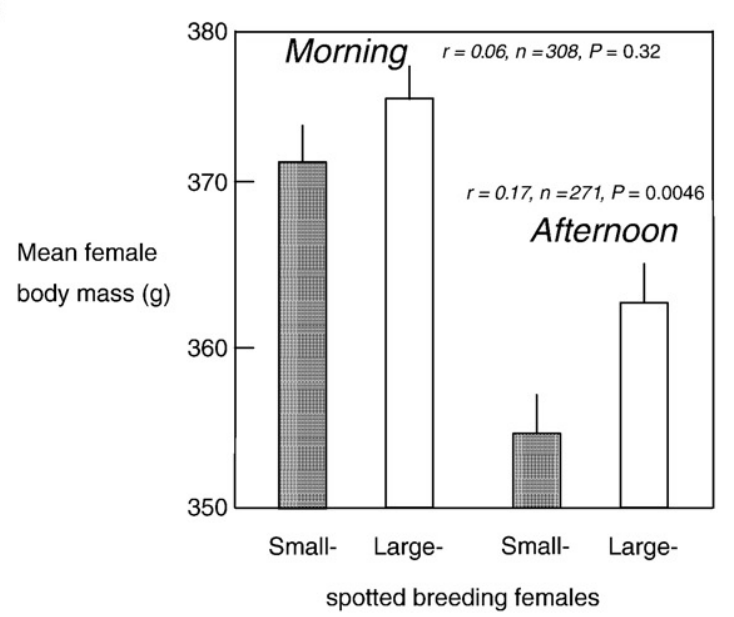

Fig. 3. Experimental test of the prediction that compared to pale individuals, darker eumelanic barn owls better regulate the balance between food intake and energy expenditure. (A) Nestlings displaying large black spots consumed fewer mice over a period of $24 \mathrm{~h}$ than conspecifics with smaller black spots (adapted from Dreiss et al., 2010). (B) When food-deprived during $24 \mathrm{~h}$, nestlings displaying large black spots lost less weight than individuals showing smaller spots (adapted from Dreiss et al., 2010). (C) Females displaying large black spots are significantly heavier than females with small spots in the afternoon but not in the morning (adapted from Roulin, 2009).

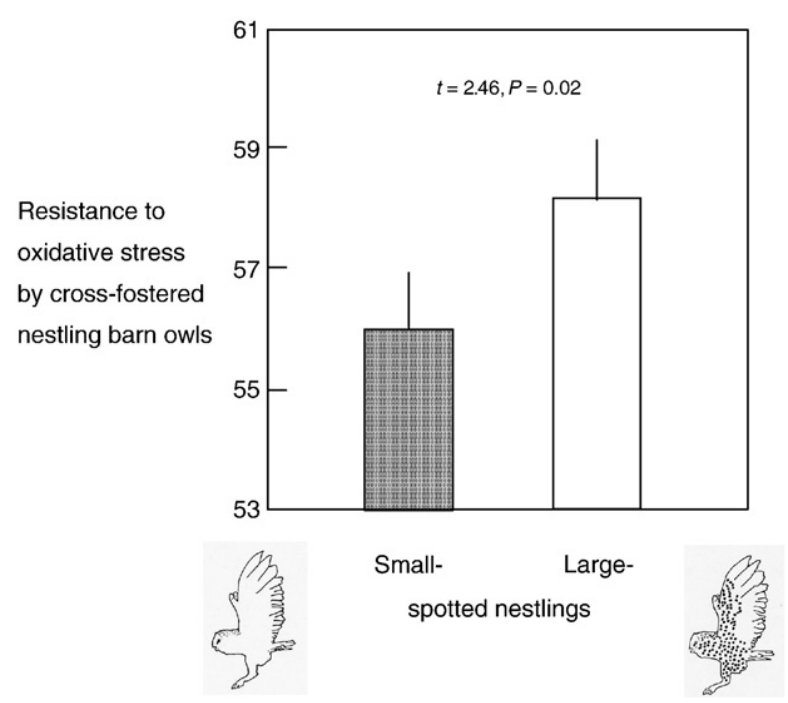

Fig. 4. Experimental test of the prediction that compared to pale individuals, darker eumelanic barn owls are more resistant to oxidative stress. As a measure of oxidative stress we considered the time needed to hemolyze $50 \%$ of the red blood cells exposed to a controlled attack by reactive oxygen species using the KRL bioassay. Red blood cells of nestlings raised by foster parents took more time to lyse after an attack by reactive oxygen species when displaying large than small black spots (adapted from unpubl. data).

More than 100 genes regulate melanic pigmentation (Bennet and Lamoreux, 2003), and the products of some of these genes result in the same coloration (Manceau et al., 2010). Different genetic solutions to obtain similar pigment patterns may evolve if genes involved in the production of these pigments do not have pleiotropic effects. In the case, these genes pleiotropically regulate several physiological functions beyond melanogenesis, the evolution of alternative genetic solutions to produce similar pigmentation would not be selectively equivalent. This is a fascinating avenue that requires precise knowledge of the exact genes responsible for variation in melanin-based coloration in several populations of the same species, combined with detailed observation about the phenotypic correlates of melanic coloration in these populations. An appropriate species to carry out such a study is the free-living beach mice (Peromyscus polionotus) in which Steiner et al. (2009) found that different populations display

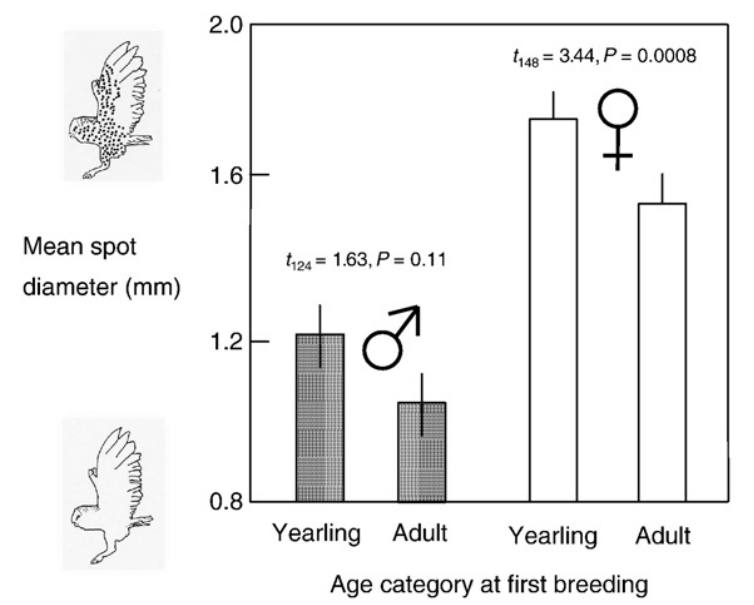

Fig. 5. Test of the prediction that compared to pale individuals, darker eumelanic barn owls are sexually more active. Females displaying large black spots started to breed for the first time in their life at an earlier age than females showing smaller spots (adapted from Roulin and Altwegg, 2007). 
similar coloration, which result from mutations located in different genes, namely Mc1r and ASIP genes. Because the Mc1r gene has limited pleiotropic effects, while the ASIP gene is known to alter several phenotypes (Ducrest et al., 2008), it is possible that these alternative genetic solutions to produce similar pigmentation have evolved under natural selection.

\subsection{Pharmacological implications}

Studies performed in the barn owl showed that physiological traits measured in nestlings are associated with the size of eumelanic spots located at the tip of feathers displayed by themselves (Figs. 1C, $3 \mathrm{~A}, \mathrm{~B}$ ) or by their biological mother (Figs. 1A, B, E, 2A, 2B) but not by their biological father. Because nestlings were raised by foster parents, the link between phenotypic traits and maternal spot diameter could be due either to a pre-hatching maternal effect or by genomic imprinting. Under the first scenario, large-spotted mothers add biochemicals in their eggs that alter the development of their offspring. For instance, larger-spotted mothers may pack more melanocortin hormones (or other hormones that alter the expression of the offspring POMC gene, see Halasz et al., 1997) in their eggs that improve the development of the offspring immune system potentially explaining why offspring born from heavily spotted mothers produce more antibodies towards a specific antigen (Fig. 2A) and are better able to reduce the fecundity of ectoparasites probably because parasites are less able to extract resources from their host (Fig. 2B). This hypothesis is plausible because barn owl females have already been shown to invest differentially in reproduction in relation to the size of their black spots by modifying offspring sex ratio (Roulin et al., 2010). Under the scenario of genomic imprinting only the gene copy inherited from the mother is expressed explaining why phenotypic traits measured in the offspring are correlated with maternal but not paternal spot diameter. This scenario is possible because several studies have shown parent-of-origin expression of the ASIP gene (i.e. genetic imprinting) (Chong et al., 2007; Cropley and Martin, 2007). The barn owl therefore appears to be an interesting model system to further study whether the expression of the POMC and ASIP genes differs between the copies inherited from the mother and father.

The hypothesis that covariation between phenotypic traits and melanin coloration stems from the melanocortin system is based on the key assumption that the expression of the POMC or ASIP genes in the skins where melanic pigments are produced is correlated with the expression of the same genes in other parts of the body which controls other phenotypes. Even if different levels of melanocortin hormones can be found in different tissues at different times, the key issue is to examine whether across healthy individuals melanocortin levels measured in different tissues are correlated. Unfortunately, we are not aware of any study that examined the existence of such correlations.

We hope that this review will convince molecular biologists, pharmacologists and evolutionary biologists that bridges should be built between their fields to gain new insight into the importance of the melanocortin system in evolutionary and ecological processes.

\section{Acknowledgements}

This research was financed by the Swiss National Science Foundation supported this study financially (grant no. 31003A_120517 to AR). We are grateful to an anonymous referee for the helpful comments.

\section{References}

Almasi, B., Jenni, L., Jenni-Eiermann, S., Roulin, A., 2010. Regulation of stress response is heritable and functionally linked to melanin-based coloration. J. Evol. Biol. 23, 987-996.
Almasi, B., Roulin, A., Jenni-Eiermann, S., Jenni, L., 2008. Parental investment and its sensitivity to corticosterone is linked to melanin-based coloration in barn owls. Horm. Behav. 54, 217-223.

Bennet, D.C., Lamoreux, M.L., 2003. The color loci of mice - a genetic century. Pigment Cell Res. 16, 333-344.

Bertile, F., Oudart, H., Criscuolo, F., Le Maho, Y., Raclot, T., 2003. Hypothalamic gene expression in long-term fasted rats: relationship with body fat. Biochem. Biophys. Res. Commun. 303, 1106-1113.

Chong, S.Y., Vickaryous, N., Ashe, A., Zamudio, N., Youngson, N., Hemley, S., Stopka, T., Skoultchi, A., Matthews, J., Scott, H.S., de Kretser, D., O'Bryan, M., Blewitt, M., Whitelaw, E., 2007. Modifiers of epigenetic reprogramming show paternal effects in the mouse. Nat. Genet. 39, 614-622.

Cropley, J.E., Martin, D.I.K., 2007. Controlling elements are wild cards in the epigenomic deck. Proc. Natl Acad. Sci. USA 104, 18879-18880.

Dallman, M.F., Akana, S.F., Bhatnagar, S., Bell, M.E., Choi, S., Chu, A., Horsley, C., Levin, N., Meijer, O., Soriano, L.R., Strack, A.M., Viau, V., 1999. Starvation: early signals, sensors, and sequelae. Endocrinology 140, 4015-4023.

Dreiss, A., Henry, I., Ruppli, C., Almasi, B., Roulin, A., 2010. Darker eumelanic barn owls better withstand food depletion through resistance to food deprivation and lower appetite. Oecologia 164, 65-71.

Ducrest, A.L., Keller, L., Roulin, A., 2008. Pleiotropy in the melanocortin system, coloration and behavioural syndromes. Trends Ecol. Evol. 23, 502-510.

Eberle, A.N., 1988. The melanotropins: chemistry, physiology and mechanism of action. Karger.

Ellis, C., Moar, K.M., Logie, T.J., Ross, A.W., Morgan, P.J., Mercer, J.G., 2008. Diurnal profiles of hypothalamic energy balance gene expression with photoperiod manipulation in the Siberian hamster, Phodopus sungorus. Am. J. Physiol. Regul. Integr. Comp. Physiol. 294, 1148-1153.

Galvan, I., Alonso-Alvarez, C., 2008. An intracellular antioxidant determines the expression of a melanin-based signal in a bird. PlosOne 3, e3335.

Gasparini, J., Bize, P., Piault, R., Kazumasa, W., Blount, J., Roulin, A., 2009. Strength and cost of mounting an immune response are associated with a heritable melaninbased color trait in female tawny owls. J. Anim. Ecol. 78, 608-616.

Halasz, I, Rittenhouse, P.A. Zorrilla, E.P., Redei, E. 1997. Sexually dimorphic effects of maternal adrenalectomy on hypothalamic corticotrophin-releasing factor, glucocorticoid receptor and anterior pituitary POMC mRNA levels in rat neonates. Dev. Brain Res. 100, 198-204.

Hoglund, E., Balm, P.H.M., Winberg, S., 2000. Skin darkening, a potential social signal in subordinate arctic charr (Salvelinus alpinus): the regulatory role of brain monoamines and pro-opiomelanocortin-derived peptides. J. Exp. Biol. 203, 1711-1721.

Jablonski, N.G., Chaplin, G., 2010. Human skin pigmentation as an adaptation to UV radiation. Proc. Acad. Natl. Sci. USA 107, 8962-8968.

Kappeler, L., Zizzari, P., Grouselle, D., Epelbaum, J., Bluet-Pajot, M.T., 2004. Plasma and hypothalamic peptide-hormone levels regulating somatotroph function and energy balance in fed and fasted states: a comparative study in four strains of rats. J. Neuroendocrinol. 16, 980-988.

Manceau, M., Domingues, V.S., Linnen, C.R., Rosenblum, E.B., Hoekstra, H., 2010. Convergence in pigmentation at multiple levels: mutations, genes and function. Phil. Trans. R. Soc. B365, 2439-2450.

Mullen, L.M., Hoekstra, H.E., 2008. Natural selection along an environmental gradient: a classical cline in mouse pigmentation. Evolution 62, 1555-1569.

Müller, C., Almasi, B., Roulin, A., Breuner, C.W., Jenni-Eiermann, S., Jenni, L., 2009. Effects of corticosterone pellets on baseline and stress-induced corticosterone and corticosteroid-binding-globulin. Gen. Comp. Endocrinol. 160, 59-66.

Myers, D.A., Bell, P.A., Hyatt, K., Mlynarczyk, M., Ducsay, C.A., 2005. Long term hypoxia enhances proopiomelanocortin processing in the near-term ovine fetus. Am. J. Physiol. Regul. Integr. Comp. Physiol. 288, R1178-R1184.

Palermo, F., Nabissi, M., Cardinaletti, G., Tibaldi, E., Mosconi, G., Polzonetti-Magni, A.M., 2008. Cloning of sole proopiomelanocortin (POMC) cDNA and the effects of stocking density on POMC mRNA and growth rate in sole, Solea solea. Gen. Comp. Endocrinol. 155, 227-233.

Rees, J.L., 2003. Genetics of hair and skin color. Ann. Rev. Genet. 37, 67-90.

Roulin, A., 1999. Nonrandom pairing by male barn owls Tyto alba with respect to a female plumage trait. Behav. Ecol. 10, 688-695.

Roulin, A., 2004. Proximate basis of the covariation between a melanin-based female ornament and offspring quality. Oecologia $140,668-675$.

Roulin, A., 2009. Covariation between eumelanic pigmentation and body mass only under specific conditions. Naturwiss. 96, 375-382.

Roulin, A., Altwegg, R., 2007. Breeding rate is associated with pheomelanism in male and with eumelanism in female barn owls. Behav. Ecol. 18, 563-570.

Roulin, A., Dijsktra, C., 2003. Genetic and environmental components of variation in eumelanin and phaeomelanin sex-traits in the barn owl. Heredity 90, 359-364.

Roulin, A., Altwegg, R., Jensen, H., Steinsland, I., 2010. Sex-dependent selection on an autosomal melanic female ornament promotes the evolution of sex ratio bias. Ecol. Lett. 13, 616-626.

Roulin, A., Christe, P., Dijkstra, C., Ducrest, A.-L., Jungi, T.W., 2007. Origin-related, environmental, sex, and age determinants of immunocompetence, susceptibility to ectoparasites and disease symptoms in the barn owl. Biol. J. Lin. Soc. 90, $703-718$.

Roulin, A., Ducrest, A.-L., Balloux, F., Dijkstra, C., Riols, C., 2003. A female melaninornament signals offspring fluctuating asymmetry in the barn owl. Proc. R. Soc. Lond. B270, 167-171.

Roulin, A., Emaresi, G., Bize, P., Gasparini, J., Piault, R., Ducrest, A.-L., in press. Pale and dark reddish melanic tawny owls differentially regulate the level of blood circulating POMC prohormone in relation to environmental conditions. Oecologica. 
Roulin, A., Jungi, T.W., Pfister, H., Dijkstra, C., 2000. Female barn owls (Tyto alba) advertise good genes. Proc. R. Soc. Lond. B267, 937-941.

Roulin, A., Riols, C., Dijkstra, C., Ducrest, A.-L., 2001. Female plumage spottiness and parasite resistance in the barn owl (Tyto alba). Behav. Ecol. 12, 103-110.

Rousseau, K., Kauser, S., Pritchard, L.E., Warhurst, A., Oliver, R.L., Slominski, A., Wei, E.T., Thody, A.J., Tobin, D.J., White, A., 2007. Proopiomelanocortin (POMC), the ACTH/ melanocortin precursor, is secreted by human epidermal keratinocytes and melanocytes and stimulates melanogenesis. FASEB 21, 1844-1856.

Schioth, H.B., Haitina, T., Ling, M., Ringholm, A., Fredriksson, R., Cerda-Reverter, J.M., Klovins, J., 2005. Evolutionary conservation of the structural, pharmacological, and genomic characteristics of the melanocortin receptor subtypes. Peptides 26, 1886-1900.

Schwartz, M.W., Porte, D., 2005. Diabetes, obesity, and the brain. Science 307, 375-379. Slominski, A., 2005. Neuroendocrine system of the skin. Dermatology 211, 199-208.
Slominski, A., Wortsman, J., 2000. Neuroendocrinology of the skin. Endocr. Rev. 21,457-487. Slominski, A., Wortsman, J., Luger, T., Paus, R., Solomon, S., 2000. Corticotropin releasing hormone and proopiomelanocortin involvement in the cutaneous response to stress. Physiol. Rev. 80, 970-1020.

Steiner, C.C., Rompler, H., Boettger, L.M., Schoneberg, T., Hoekstra, H.E., 2009. The genetic basis of phenotypic convergence in beach mice: similar pigment patterns but different genes. Mol. Biol. Evol. 26, 35-45.

Sturm, R.A., 2006. A golden age of human pigmentation genetics. Trends Genet. 22, 464-468. Valverde, P., Healy, E., Jackson, I., Rees, J.L., Thody, A.J., 1995. Variants of the melanocytestimulating hormone receptor gene are associated with red hair and fair skin in humans. Nat. Genet. 11, 328-330.

Zbytek, B., Wortsman, J., Slominski, A., 2006. Characterization of a ultraviolet B-induced corticotropin-releasing hormone-proopiomelanocortin system in human melanocytes. Mol. Endocrinol. 20, 2539-2547. 